\title{
Online derivatization for hourly measurements of gas- and particle-phase semi-volatile oxygenated organic compounds by thermal desorption aerosol gas chromatography (SV-TAG)
}

\author{
G. Isaacman ${ }^{1}$, N. M. Kreisberg ${ }^{2}$, L. D. Yee ${ }^{1}$, D. R. Worton ${ }^{1,2}$, A. W. H. Chan ${ }^{1, *}$, J. A. Moss ${ }^{1}$, S. V. Hering ${ }^{2}$, and \\ A. H. Goldstein ${ }^{1,3}$ \\ ${ }^{1}$ Department of Environmental Science, Policy, and Management, University of California, Berkeley, CA, USA \\ ${ }^{2}$ Aerosol Dynamics Inc., Berkeley, CA, USA \\ ${ }^{3}$ Department of Civil and Environmental Engineering, University of California, Berkeley, CA, USA \\ * now at: Department of Chemical Engineering and Applied Chemistry, University of Toronto, Toronto, Canada
}

Correspondence to: G. Isaacman (gabriel.isaacman@berkeley.edu)

Received: 22 May 2014 - Published in Atmos. Meas. Tech. Discuss.: 23 July 2014

Revised: 23 October 2014 - Accepted: 29 October 2014 - Published: 12 December 2014

\begin{abstract}
Laboratory oxidation studies have identified a large number of oxygenated organic compounds that can be used as tracers to understand sources and oxidation chemistry of atmospheric particulate matter. Quantification of these compounds in ambient environments has traditionally relied on low-time-resolution collection of filter samples followed by offline sample treatment with a derivatizing agent to allow analysis by gas chromatography of otherwise non-elutable organic chemicals with hydroxyl groups. We present here an automated in situ instrument for the measurement of highly polar organic semi-volatile and low-volatility compounds in both the gas- and particle-phase with hourly quantification of mass concentrations and gas-particle partitioning. The dual-cell semi-volatile thermal desorption aerosol gas chromatograph (SV-TAG) with derivatization collects particle-only and combined particle-plus-vapor samples on two parallel sampling cells that are analyzed in series by thermal desorption into helium saturated with derivatizing agent. Introduction of MSTFA (N-methyl-N(trimethylsilyl)trifluoroacetamide), a silylating agent, yields complete derivatization of all tested compounds, including alkanoic acids, polyols, diacids, sugars, and multifunctional compounds. In laboratory tests, derivatization is found to be highly reproducible ( $<3 \%$ variability). During field deployment, a regularly injected internal standard is used to correct for variability in detector response, consumption of the derivatization agent, desorption efficiency, and transfer
\end{abstract}

losses. Error in quantification from instrument fluctuations is found to be less than $10 \%$ for hydrocarbons and less than $15 \%$ for all oxygenates for which a functionally similar internal standard is available, with an uncertainty of 20-25\% in measurements of particle fraction. After internal standard corrections, calibration curves are found to be linear for all compounds over the span of 1 month, with comparable response on both of the parallel sampling cells.

\section{Introduction}

In both urban and rural environments, the majority of submicron particulate matter is organic (Jimenez et al., 2009; Zhang et al., 2007), mostly formed through the oxidative conversion of gas-phase anthropogenic and biogenic emissions into secondary organic aerosols (SOA) (Goldstein and Galbally, 2007; Hallquist et al., 2009; Kroll and Seinfeld, 2008). One of the primary tools to understand oxidation pathways and source apportionment is the measurement of organic tracers: compounds known to come from specific emission sources and/or form through oxidation under specific conditions. Tracers are typically quantified using samples collected on traps or filters and extracted with solvents or thermally desorbed to be analyzed by gas or liquid chromatography (GC, LC) coupled to a mass spectrometer (MS) (Cass, 1998; Hamilton, 2010; Mazurek, 2002; Schauer et al., 
1996; Simoneit, 2005). These tracers include non-polar compounds such as hydrocarbons that are conducive to analysis by GC-MS without extensive sample preparation, as well as polar compounds that require analysis by LC-MS or treatment with a derivatizing agent prior to GC analysis.

For GC analysis, filter samples are typically reacted with a derivatizing agent following solvent extraction to form esters and ethers from hydroxyl groups, which suffer from poor transfer through GC columns due to hydrogen bonding interactions. Diazomethane, a common derivatizing agent, selectively converts acid groups into methyl esters and has been used to quantify acids and diacids in petroleum sources (Fraser et al., 1998; Schauer et al., 1999b, 2002), meat cooking (Schauer et al., 1999a), and biological processes (Simoneit, 2005). Source profiles containing these derivatized acids in combination with hydrocarbons (including alkanes, hopanes, steranes, and polycyclic aromatic hydrocarbons), and biomass-burning tracers (Fraser and Lakshmanan, 2000; Ramdahl, 1983) have been used extensively in the analysis of particulate matter in urban environments (Fraser et al., 1999; Hildemann et al., 1991; Kubátová et al., 2002; Lough et al., 2006). Alternately, derivatization can be performed using silylating agents, which exhibit broader reactivity, converting all $\mathrm{OH}$ groups into silyl esters and ethers. A large number of such reagents are available with minor variations in volatility and reactivity (Fluka Chemie AG, 1995), but the most commonly used in atmospheric applications is BSTFA (N,O-bis(trimethylsilyl)trifluoroacetamide), which yields trimethylsilyl (TMS) protecting groups as a derivatized product. Using BSTFA derivatization, many compounds have been identified in the laboratory-controlled oxidation of common biogenically emitted compounds, including isoprene (Chan et al., 2010; Claeys et al., 2004; Kleindienst et al., 2009; Szmigielski et al., 2007), some monoterpenes (Claeys et al., 2007, 2009; Jaoui et al., 2005), and some sesquiterpenes ( $\beta$-caryophyllene; Jaoui et al., 2007); these tracers are regularly used for source apportionment in rural environments (i.e., Edney et al., 2003; Kleindienst et al., 2007, 2010; Kourtchev et al., 2005; Lewandowski et al., 2007; Offenberg et al., 2011; Zhang et al., 2009). Analysis by LC-MS allows measurement without prior derivatization of these and similar tracers, including compounds not observable by GC-MS (i.e., Gao et al., 2006; Surratt et al., 2008), but this technique is typically less comprehensive than derivatized GC-MS. LC analyses rely on careful selection of an elution solvent and, in most cases, quantification using electrospray ionization (ESI) MS, which is highly structurally dependent (Oss et al., 2010). Consequently the technique has focused primarily on high-molecular-weight compounds and oligomerization processes (Hallquist et al., 2009), which cannot be well studied using GC-MS.

Derivatization can be performed in situ without the need for solvent extraction and offline reaction. Docherty and Ziemann (2001) demonstrated that co-injecting BSTFA into a hot GC inlet alongside the sample efficiently derivatizes or- ganic acids, which is thought to proceed by fast reactions occurring in the gas phase after volatilization of the derivatizing agent and the analytes. Desorption of filters into a stream of derivatizing agent has been used in the analysis of atmospheric samples and laboratory oxidation experiments using both diazomethane (Sheesley et al., 2010) and silylating agents (Orasche et al., 2011; Ruehl et al., 2013; Zhang et al., 2013), but it is not yet a widely used technique.

Since most previous particle-phase tracer measurements have relied upon offline analysis, the time resolution of sample collection has typically been on the order of several hours to several days. Through development of the thermal desorption aerosol gas chromatograph (TAG), Williams and co-workers (Kreisberg et al., 2009; Williams et al., 2006) were able to measure non-polar and low-polarity tracers with hourly time resolution, resulting in insights into particle formation pathways and source apportionment (Williams et al., 2010a, b; Worton et al., 2011). A newer version of this instrument uses a high-surface-area filter to collect gas- and particle-phase low-volatility and semi-volatile compounds, considered here as any compounds expected to partition between the gas and particle phase under typical atmospheric conditions (SV-TAG; described by Zhao et al., 2013b). This has expanded the utility of this instrument into measurements of gas-to-particle conversion pathways (Zhao et al., 2013a). However, while this instrument provides the highest available time resolution for the measurement of organic tracer compounds, it has thus far been limited to hydrocarbons and less-polar oxygenates (oxygen-to-carbon ratio lower than 0.3 in most cases). Most known tracers for the oxidation of biogenic compounds are too polar to be measured by previous TAG instruments, as they often exhibit an oxygen-to-carbon ratio between 0.5 and 1 .

Here we describe modifications to SV-TAG (semi-volatile thermal desorption aerosol gas chromatograph) to enable measurements of highly polar oxygenates with hourly time resolution through the inclusion of in situ derivatization. To validate the implementation, we demonstrate here that derivatization occurs to completion, yields linear calibrations, and is reproducible. We also present a rigorous quantification of error for calibrated data.

\section{Methods}

\subsection{SV-TAG overview}

The instrument described in this work is shown in Fig. 1. Briefly, it is a modified SV-TAG, a custom in situ instrument for quantifying gas- and particle-phase semi- and lowvolatility organic compounds in the atmosphere (Kreisberg et al., 2009; Williams et al., 2006; Zhao et al., 2013b). SVTAG measures organic compounds in both the gas and particle phase through collection onto a custom collection cell containing a reusable, high-surface-area metal fiber filter, the 

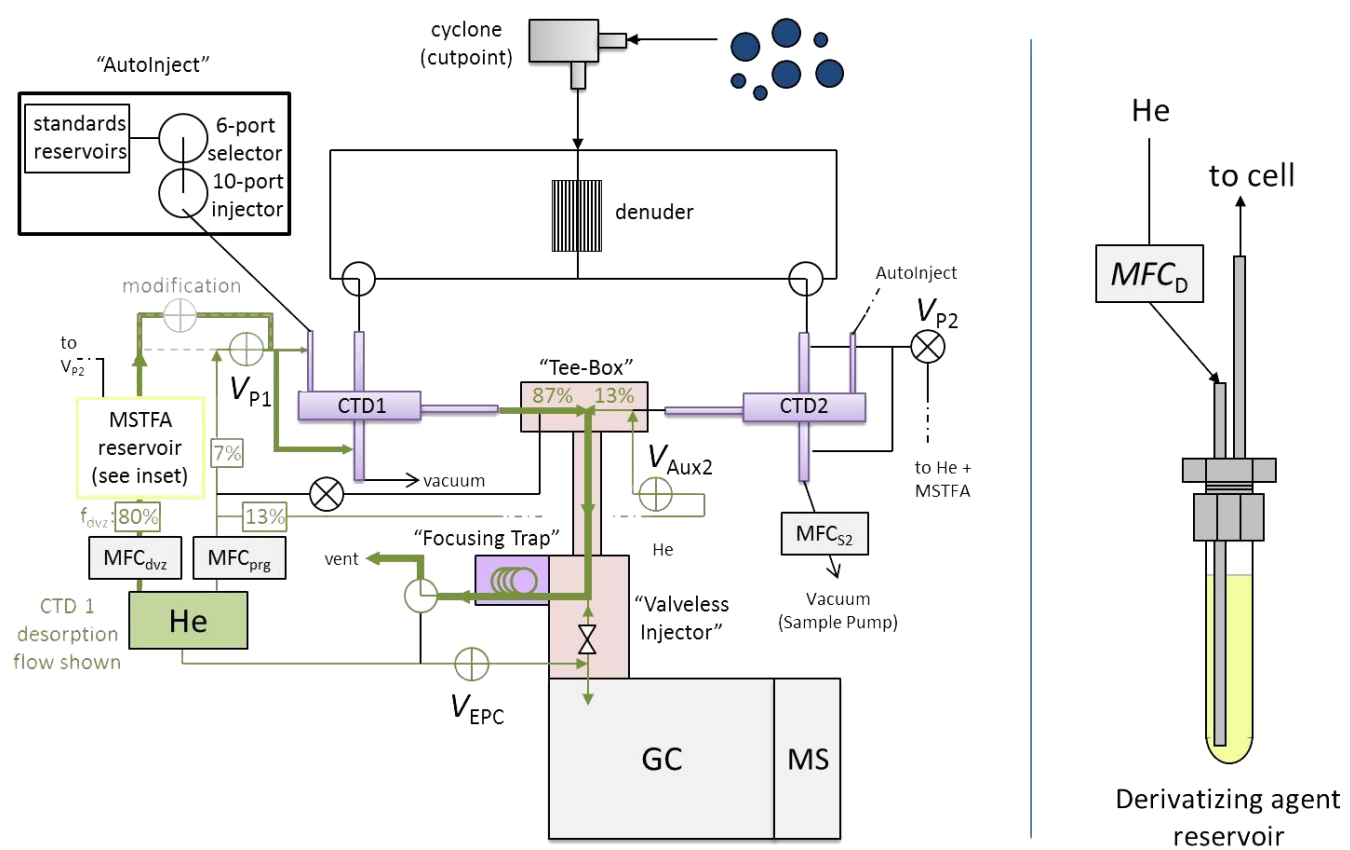

Figure 1. Schematic of dual-cell SV-TAG with in situ derivatization. Two parallel collection and thermal desorption cells (CTD) simultaneously sample, one directly collecting gas-plus-particle-phase compounds and one through a denuder that removes all gas-phase compounds, thus collecting only particles. Each sample is transferred in series to the GC-MS through a two-stage purge-and-trap thermal desorption process. Purge helium is saturated with derivatization agent by passing through a reagent reservoir (inset). Derivatized and underivatized desorption flows are controlled independently using $\mathrm{MFC}_{\mathrm{dvz}}$ and $\mathrm{MFC}_{\mathrm{prg}}$, respectively. Liquid standards are regularly introduced by the AutoInject. After SOAS, derivatized flow paths were decoupled from non-derivatized flow paths (modification shown in dashed gray - path with flow added, path without flow removed). Green arrows show helium flow during desorption of CTD1 assuming $f_{\mathrm{dvz}}=0.80$, where width is approximate relative to flow rate.

implementation and operation of which is described in detail by Zhao et al. (2013b). Two identical cells are used in parallel to collect simultaneous measurements with and without passing through a denuder to directly measure gasparticle partitioning. Thermal desorption of these compounds includes in situ derivatization and subsequent analysis by gas chromatography-mass spectrometry. Quantification of mass concentration and particle fraction is achieved with hourly time resolution. The implementation of two important novel instrument components is described and validated here: parallel dual-cell sampling system (Sect. 2.1.2) and in situ derivatization (Sect. 2.1.3).

\subsubsection{Description of SV-TAG and operation}

Sample is collected at $10 \mathrm{~L} \mathrm{~min}^{-1}$ into a custom collection and thermal desorption cell (CTD), which contains a highsurface-area metal fiber filter in a housing that can be cooled through forced air cooling, or heated. This filter CTD (FCTD) quantitatively collects gas-phase compounds with a volatility as high as tetradecane, which is found almost entirely (>99\%) in the gas phase under ambient conditions (Zhao et al., 2013b). In sampling or analysis scenarios not requiring gas-phase collection, the original impactor CTD (I-CTD) can be installed, which can be more easily cleaned of nonvolatile contaminants such as black carbon. For field measurements, this work uses an F-CTD to collect gas-phase compounds. As noted, some lab experiments reported in this work utilize the I-CTD. Samples can be collected directly or by first passing through a 500-channel activated carbon denuder (30 mm outside-diameter (OD) $\times 40.6 \mathrm{~cm}$; MAST Carbon), shown to efficiently remove gas-phase species (Zhao et al., 2013b). Comparison between undenuded ("total", gasplus-particle) samples and denuded ("particle") samples provides a direct measurement of gas-particle partitioning of semi-volatile compounds, an area of active research. Simultaneous dual-cell collection removes the need for interpolation between consecutive samples to quantify gas-particle partitioning. Gas-particle partitioning is measured using a denuder-difference technique, which is expected to result in lower error than a filter-difference measurement, as is discussed in detail by Zhao et al. (2013b). Briefly, filter-based removal of particles is expected to result in adsorption and possible re-volatilization of low-volatility gases resulting in positive artifacts (Storey et al., 1995). Negative artifacts from sampling through a denuder have been suggested as a potential source of error, such as removal of particle-phase compounds from volatilization in the denuder due to the removal of the gas phase (Kamens and Coe, 1997). These artifacts are 
minimized in this instrument by keeping denuder residence time low $(\sim 1 \mathrm{~s})$. Vapors are efficiently collected and retained on the F-CTD through long periods of sample collection, so loss of gas-phase compounds during sampling is expected to be negligible (Zhao et al., 2013b).

Samples are transferred from the CTD to the GC-MS in a two-step thermal desorption process. First, compounds are desorbed from the cell into a stream of helium saturated with a variable quantity of derivatizing agent, ramping between 30 and $315^{\circ} \mathrm{C}$ over $8 \mathrm{~min}$ with relatively high helium flow rates $(20-150 \mathrm{sccm}$ two-stage desorption flow as described by Zhao et al., 2013b), and re-concentrated onto a focusing trap that is held at $30^{\circ} \mathrm{C}$ through forced air cooling. This focusing trap, consisting of approximately $100 \mathrm{~cm}$ of metal, thick phase column (MXT-5, $0.53 \mathrm{~mm}$ inside-diameter (ID) $\times 5 \mu \mathrm{m}$ phase thickness; Restek), is then heated to $315^{\circ} \mathrm{C}$ for $5 \mathrm{~min}$ and back-flushed $(\sim 2 \mathrm{sccm})$ through a custom valveless interface (Kreisberg et al., 2014) onto the head of the GC column for analysis by mass spectrometry. For this work a non-polar column (Rtx-5Sil MS, $20 \mathrm{~m} \times 0.18 \mathrm{~mm} \times 0.18 \mu \mathrm{m}$; Restek) was installed in a gas chromatograph (7890A; Agilent Technologies) modified to accommodate SV-TAG hardware, coupled to a commercially available mass spectrometer (5975C; Agilent Technologies). GC analysis of each sample occurs in $14 \mathrm{~min}$, with a ramp of $23.6^{\circ} \mathrm{C} \mathrm{min}^{-1}$ from 50 to $330^{\circ} \mathrm{C}$ (hold $2.2 \mathrm{~min}$ ) and a helium flow rate of $1 \mathrm{sccm}$. Analysis is performed with custom software written in Igor Pro 6.3 (Wavemetrics).

Calibration and correction for run-to-run variability is performed through regular injection of liquid standards into the CTD using an automatic injection system ("AutoInject"). A two-position valve containing a $4 \mu \mathrm{L}$ sample loop is loaded from any one of multiple chilled reservoirs holding the standards (details in Isaacman et al., 2011). For the dual-cell system, a 10-port, 2-position valve containing two standard loops of the same volume was used, one for each cell. Both standard loops are loaded simultaneously, with the same standard then injected at the same time into their respective cells immediately following sampling so that the samples and the internal standards are subjected to the same conditions. Natural variability in atmospheric concentrations, and therefore sample mass, can affect transfer efficiency - desorption efficiency and transfer losses between the cell and the GCMS - as well as consumption of derivatizing agent (i.e., more $\mathrm{OH}$ groups requires more reagent). These variables, as well as fluctuations in GC-MS sensitivity, are corrected for using approximately 25 isotopically labeled (mostly perdeuterated) standards representing most atmospherically relevant functional groups that are introduced into every sample. Calibrations are performed using more than 100 authentic standards spanning a broad range of functional groups and known tracer compounds. Calibration injections are performed approximately once every $6-8 \mathrm{~h}$ at different concentrations to yield a multi-point calibration approximately every day or two. All chemical standards used were purchased at $>98 \%$ purity from Sigma-Aldrich or C/D/N Isotopes.

\subsubsection{Implementation of dual-cell system}

Outfitting SV-TAG with a parallel dual-cell system provides flexibility for improved measurements and detailed method comparisons. Parallel cells are sampled simultaneously and then analyzed in series; samples can be collected or analyzed in two different ways. In a typical field deployment, gasparticle partitioning is targeted by collecting samples with different treatments: one cell collects an undenuded sample (gas-plus-particle), while the other collects a denuded sample (particle-only, all gas-phase species removed). The roles of the cells are swapped with each sample to avoid cell-tocell bias. The dual-cell SV-TAG instrument can therefore directly measure gas-particle partitioning without any need for interpolation between points, a source of error in previous measurements of partitioning with TAG (Williams et al., 2010a; Worton et al., 2011; Zhao et al., 2013a). Alternately, when comparing methods of derivatization, each cell can be subjected to different treatments (i.e., derivatized and nonderivatized), allowing direct comparison between methods on ambient samples.

To ensure the identical sample size of each cell, sample flow is regulated independently through two matching mass flow controllers (e.g., $\mathrm{MFC}_{\mathrm{S} 2}$ shown for cell 2). For thermal desorption, the cells are joined to the valveless interface via a custom "tee-box" manifold (Fig. 1) consisting of three $1 / 16$ in. passivated VICI tees in a housing maintained at $300{ }^{\circ} \mathrm{C}$, which allows desorption of one cell at a time. During desorption of CTD1, used as an example in Fig. 1, helium from valve $V_{\mathrm{P} 1}$ purges CTD1, while the purge valve on CTD2, $V_{\mathrm{P} 2}$, is closed to prevent accidental transfer of volatiles. Desorption helium flushes the collection cell from both above and below the internal collection filter, with the split between these flow paths governed by restrictive capillaries as described by Zhao et al. (2013b); substantially more flow passes through the filter from below as shown by differences in arrow widths in Fig. 1. During desorption, helium also flows through auxiliary flow valve $V_{\text {Aux2, which intro- }}$ duces flow downstream of CTD2 to prevent any desorption flow from CTD1 reaching CTD2. Using restrictive capillaries, a passive 1:7 split between the flow paths of $V_{\mathrm{P} 1}$ and $V_{\text {Aux2 }}$ ensures that $13 \%$ of total purge flow goes through the auxiliary channel, with the other $87 \%$ divided between derivatized and underivatized purge flow. This auxiliary flow prevents cell-to-cell contamination with $>97 \%$ efficiency (Kreisberg et al., 2014).

A typical duty cycle consists of $22 \mathrm{~min}$ of sampling on both cells, injection of standards ( $2 \mathrm{~min}$ ), two-step desorption (12 min) and chromatographic analysis (14 min) of CTD1, and then desorption and analysis of CTD2, while collection of the subsequent sample begins after exactly $60 \mathrm{~min}$. The valveless interface decouples the collection cells from the 
GC, allowing hourly time resolution by performing GC-MS analysis during CTD desorption and sampling.

\subsubsection{Implementation of in situ derivatization}

Derivatization is implemented by saturating helium with derivatizing agent, and using that saturated helium as a portion of the total CTD purge flow during thermal desorption. Desorption flow is controlled as the sum of helium flow through two mass flow controllers: $\mathrm{MFC}_{\mathrm{dvz}}$, which passes through the derivatizing agent reservoir (Fig. 1 inset), and $\mathrm{MFC}_{\mathrm{prg}}$, which does not. The reservoir consists of a standard $10 \mathrm{~mm} \times 75 \mathrm{~mm}$ glass test tube with a custom modified compression fitting cap (Swagelok) with two 1/16 in. OD tubes inserted and soldered. Helium is introduced at the bottom of the reservoir and bubbled through the derivatizing agent, ensuring saturation. This reservoir is the same as those used for liquid flow of standards in the AutoInject, connected in reverse to provide gas flow. A constant stream of derivatizing agent is thus introduced so that all compounds are volatilized from the CTD into an environment rich in reagent. Excess reagent passes through the focusing trap (Fig. 1) during desorption, minimizing the amount of unreacted derivatizing agent reaching the GC column. Due to this purge method, only species less volatile than the derivatizing agent can be analyzed. Derivatization occurs during the first $7 \mathrm{~min}$ of the two-step thermal desorption process, with the final minute purged without derivatizing agent to reduce introduction of reagent onto the GC column.

The quantity of derivatizing agent introduced to the sample can be optimized by controlling the fraction of total purge flow that is routed through the reagent reservoir, $f_{\mathrm{dvz}}=\mathrm{MFC}_{\mathrm{dvz}} /\left(\mathrm{MFC}_{\mathrm{dvz}}+\mathrm{MFC}_{\mathrm{prg}}\right)$. However, we describe here some limitations to this control. To prevent the derivatization of the cell that is not being desorbed, it is necessary to ensure that $V_{\text {Aux }}$ does not receive any derivatizing agent, so, due to the $1: 7$ passive split, greater than $13 \%$ of total flow must be purge flow at all times. Maximum derivatization is therefore $f_{\mathrm{dvz}}=0.87$, though in practice $f_{\mathrm{dvz}}=0.80$ is rarely exceeded to ensure proper division of flows (illustrated in Fig. 1). To make certain that $V_{\text {Aux }}$ gets flow from $\mathrm{MFC}_{\text {prg }}$ and because surface tension in the MSTFA (N-methyl-N-(trimethylsilyl)trifluoroacetamide) reservoir prevents bubbling of $<\sim 2 \mathrm{sccm}$, neither purge nor derivatization flow are ever regulated to be between 0 and $4 \mathrm{sccm}$. The fraction of desorption flow that is derivatized at low total flows is limited by these constraints. For example, at $20 \mathrm{sccm}, f_{\mathrm{dvz}}$ cannot be greater than 0.75 or less than 0.25 , though it can be set to 0 by shutting the valve shown as a "modification" in Fig. 1. Despite these limitations, independent control of derivatized and non-derivatized flow provides a useful tool for probing derivatization efficiency (demonstrated in Sect. 3.1) and optimizing amount of reagent used. In typical collection of ambient data, $f_{\mathrm{dvz}}$ is set to the practical maximum of 0.80 to ensure complete derivatization.

\subsubsection{Selection of derivatization agent}

Dozens of derivatizing agents exist in the literature to improve GC analysis for a wide variety of functional classes (Blau and Halket, 1993), but the most commonly used reagents for atmospheric organic tracer analysis are silylating agents, primarily BSTFA, due to their efficiency and broad reactivity (all $\mathrm{OH}$ groups). As previous research has demonstrated the utility of this agent for efficient, fast, gasphase derivatization (Docherty and Ziemann, 2001), silylating agents in the chemical family of BSTFA are used in this work. MSTFA has been used for the dual-cell SV-TAG presented here due to its similar reactivity but higher reagent and byproduct volatility than BSTFA (Fluka Chemie AG, 1995), allowing all non-analytes to be efficiently purged across the focusing trap. MSTFA has an estimated vapor pressure approximately equal to decane $\left(\mathrm{C}_{10}\right.$ alkane $)$ and so is sufficiently volatile to not impede the analysis of any species targeted by SV-TAG, which is limited in its sample collection to species no more volatile than $\mathrm{C}_{14}$ alkane (Sect. 2.1.1). The implementation of in situ derivatization presented in this work allows complete flexibility of derivatizing agent and an effective means for measuring derivatization efficiency, so use of derivatizing agents targeting specific volatilities or functional groups is an area for future exploration. Derivatizing reagents were purchased through Sigma-Aldrich (> $98 \%$ purity, synthesis grade).

\subsection{Laboratory evaluation methods}

\subsubsection{Derivatization efficiency}

Derivatization efficiency was tested through repeated automatic injection of a complex mixture of polar and nonpolar compounds containing most functional groups present in known atmospheric tracer compounds and spanning a wide-range of volatilities. Response of 43 oxygenated compounds introduced by an automated liquid standard injector is examined under varying derivatization conditions. To provide a conservative test, injected quantities of most constituents were larger than expected from atmospheric sampling. Total injected mass was $2.0 \mu \mathrm{g}$ per analysis, with approximately half the mass comprised of compounds containing functional groups expected to be derivatized (hydroxyl groups). For each compound, detector response relative to detector response under high derivatization conditions $\left(f_{\mathrm{dvz}}>0.5\right)$ was measured for $8-10$ replicate injections at nine levels of MSTFA, from $1 \%$ to maximum derivatized flow $\left(f_{\mathrm{dvz}}=0.80\right)$, taking into consideration the flow limitations discussed in Sect. 2.1.3. In considering derivatization efficiency, responses of all oxygenated compounds were normalized to the nearest $n$-alkane in volatility to correct for any fluctuations in detector sensitivity and matrix-dependent transfer. A complete list of compounds injected and their relative retention times is provided in the Supplement, includ- 
ing 5 oxygenated compounds with no $\mathrm{OH}$ groups such as ketones, 25 compounds with one $\mathrm{OH}$ group, 8 compounds with two $\mathrm{OH}$ groups, and 5 compounds with three or four $\mathrm{OH}$ groups (which have been combined to improve statistics), spanning a volatility of tridecane $\left(\mathrm{C}_{13}\right.$ alkane) to tetratriacontane $\left(\mathrm{C}_{34}\right.$ alkane). While these compounds span the functionalities of most known tracers, the fate of some compound classes - i.e., hydroperoxides, organonitrates, and organosulfates - upon reaction with silylating agents is generally not well understood. Further study is necessary to understand measurement of these atmospherically relevant compounds by thermal desorption GC-MS.

\subsubsection{Derivatization reproducibility}

Under laboratory conditions, reproducibility was measured through repeated injection of an atmospheric aerosol sample: a filter extraction of a high-volume $\left(67 \mathrm{~m}^{3} \mathrm{~h}^{-1}\right)$ quartz fiber filter collected in the Sierra Nevada of California as part of the Biosphere Effects on AeRosols and Photochemistry EXperiment (BEARPEX; Worton et al., 2011). The filter was collected during the day of 1 October 2009 for approximately $11 \mathrm{~h}$ (total $726 \mathrm{~m}^{3}$ of air sampled). One-half of the filter was extracted into $50 \mathrm{~mL}$ of methanol with $1 \mathrm{~h}$ of sonication, blown dry under a gentle flow of nitrogen gas, and diluted to $10 \mathrm{~mL}$. BSTFA was introduced as a derivatizing agent for 50 consecutive injections of one AutoInject loop $(4 \mu \mathrm{L})$ into an I-CTD. In each injection, over 1400 peaks were identified above detection limits, most of which are expected to be polar compounds due to the extraction into a polar solvent. To measure reproducibility, each injection was compared to the average of all injections in the series.

Responses of internal standards over 1 month of field data during two separate field campaigns are used to estimate error in correcting for run-to-run variability and reproducibility in real-world data. Dual-cell SV-TAG with derivatization was first deployed as part of the Southern Oxidant and Aerosol Study (SOAS) in the summer of 2013 in rural Alabama $\left(32.903^{\circ} \mathrm{N}, 87.250^{\circ} \mathrm{W}\right.$, near Brent, $\left.\mathrm{AL}\right)$ in the southeastern US. The period of measurement was 1 June through 15 July 2013. Data presented here consist of calibrations and injections of internal standards from the period of 4 June-2 July 2013 ("Study 1"). Samples were collected with $1.5 \mathrm{~h}$ time resolution through 18 June 2013 and then hourly time resolution for the remainder of the field campaign. Following SOAS, minor instrument modifications were made to avoid exposing non-derivatized flow paths to derivatizing agent through the introduction of parallel flow paths and an additional valve (shown in Fig. 1 in dashed gray lines). Reproducibility and stability of the modified instrument was tested using internal standards injected on top of ambient samples collected in rural Brazil in a rainforest region from 14 February to 13 March 2014 (referred to hereafter as "Study 2"). The internal standard used during this period was an order of magnitude more dilute than that used

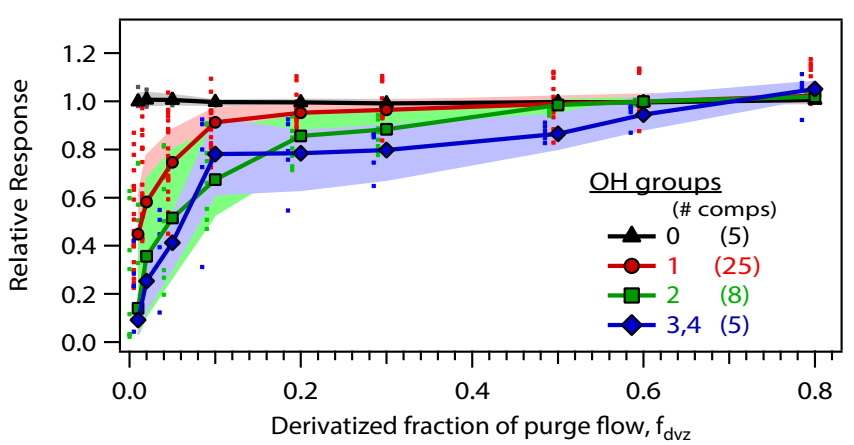

Figure 2. Response of 43 oxygenated compounds dependent on quantity of MSTFA introduced, normalized to the average response of each compound at $f_{\mathrm{dvz}}>0.5$. Solid lines and symbols are the median relative response of all injections at each derivatization level, with the interquartile range shown as the shaded area. Compounds used are listed in the Supplement. Average response of each compound at each derivatization level is shown as a small dot of the appropriate color (slightly offset to the left) to show spread of the data.

during Study 1. MSTFA was used as the derivatizing agent during both campaigns. To accommodate long-term drifts in detector sensitivity and significantly changing sample matrices, reproducibility in field data is quantified using ratios of internal standards, not simply response, the reasons and implications of which are discussed in Sect. 3.2. The internal standards used for correcting run-to-run variability in these deployments were perdeuterated $\mathrm{C}_{14}-\mathrm{C}_{32} n$-alkanes (even carbon numbers only), decanoic acid- $\mathrm{d}_{19}$, tetradecanoic acid- $\mathrm{d}_{27}$, hexadecanoic acid- $\mathrm{d}_{31}$, octadecanoic acid$\mathrm{d}_{35}$, pentadecanol- $\mathrm{d}_{31}$, cholesterol- $\mathrm{d}_{6}$ (Study 1 only), hexanedioic acid- $\mathrm{d}_{4}$, 3-hydroxy pentanedioic acid- $\mathrm{d}_{5}$, glucose${ }^{13} \mathrm{C}_{6}$ (Study 2 only), and pentaerythritol- $-2{ }^{13} \mathrm{C}$.

\section{Results and discussion}

Effective, quantitative derivatization must be shown to be complete and reproducible, with linear or predictable response. Dual-cell SV-TAG with derivatization was shown to meet these requirements through a series of laboratory tests, as well as field deployment to the southeastern US and rural Brazil.

\subsection{Derivatization efficiency}

Derivatization is shown in Fig. 2 as a function of quantity of derivatization agent introduced, and it is found to occur to completion during normal instrument operation. In a scenario of incomplete derivatization, a small reduction in reagent would be expected to reduce the response of all derivatized compounds in proportion to the number of $\mathrm{OH}$ groups on each compound. For a large number of oxygenated compounds injected into dual-cell SV-TAG, a reduction in 
signal is not observed when the fraction of derivatizing agent, $f_{\mathrm{dvz}}$, is reduced significantly from its maximum (here set at 0.80). For all 43 compounds shown, detector response leveled off by $f_{\mathrm{dvz}}=0.50$ (50\% derivatized purge flow), suggesting maximum possible derivatization, and in most cases $f_{\mathrm{dvz}}=0.30$ was a sufficient fraction of derivatization flow to maximize signal. Increased derivatization flow also decreased variability in detector response, suggesting more reproducible derivatization.

With severely reduced quantities of derivatizing agent, detector response was greatly diminished due to incomplete reaction because these compounds cannot be measured by traditional gas chromatography in the absence of derivatization. Compounds containing more hydroxyl groups are more sensitive to a dramatic reduction in $f_{\mathrm{dvz}}$, as is expected from stoichiometric limitations caused by consumption of the reagent. The injected mixture contained ketones with no hydroxyl groups to test for possible formation of a silylated enol. However, the analysis of these compounds (Fig. 2, black triangles), as well as hydrocarbons, was not found to be adversely affected by the introduction of derivatizing agent. Previous work (Orasche et al., 2011) has shown improved recovery of polycyclic aromatic hydrocarbons using derivatization, but that was neither observed nor specifically tested here.

\subsection{Reproducibility of derivatization}

Derivatization was found to be highly reproducible in a laboratory setting through the repeated injection of a complex mixture. A methanol extraction of a filter collected in the Sierra Nevada of California in the summer of 2009 was injected 50 consecutive times into an I-CTD to quantify the reproducibility of derivatization of an atmospherically relevant complex mixture (Fig. 3). Figure 3a shows a comparison of all peaks in one of these injections to the average areas, which is found to deviate from unity by less than $1 \%$, with a correlation coefficient of 0.998 , across approximately 4 orders of magnitude in peak area. These correlation metrics are consistent across all 50 injections (Fig. 3b), with a slope almost always within $2 \%$ of unity and very high correlation coefficients $\left(r^{2}>0.994\right)$. Given a $1-3 \%$ reproducibility error of the AutoInject (Isaacman et al., 2011), repeated derivatization of an identical mixture occurs with very little or no variability.

Satisfied with $>98 \%$ reproducibility under ideal laboratory conditions, reproducibility under more difficult field conditions was assessed using approximately 1 month of internal standard injections on top of ambient samples during two periods of data collection - Study 1 in the southeastern US and Study 2 in a rural Brazil rainforest region. Direct reproducibility is difficult to accomplish due to non-ideal working conditions in the field (i.e., temperature fluctuations, power outages, high humidity, drifts in detector sensitivity) and significant changes in sample loading due to atmospheric

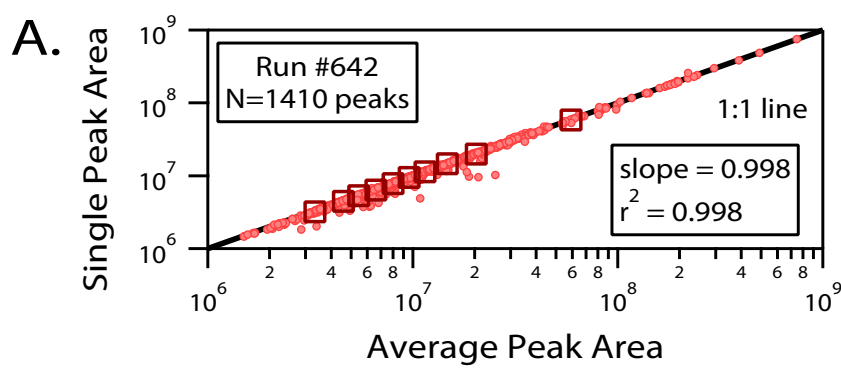

B.

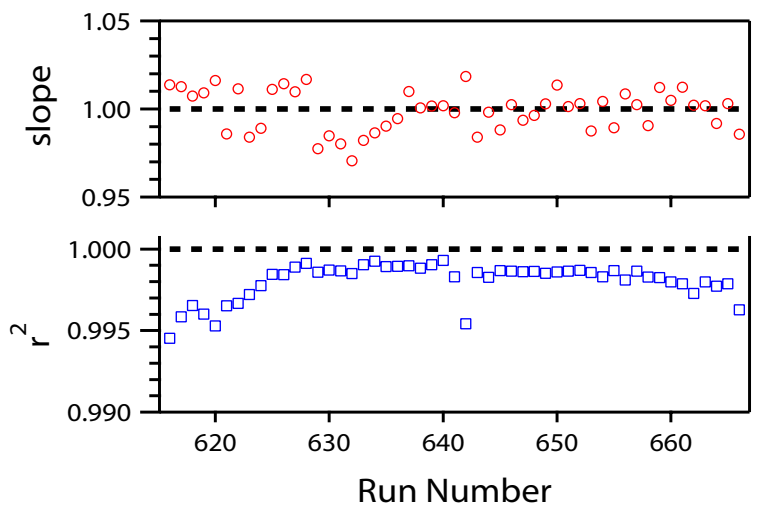

Figure 3. Comparison of reproducibility of injection and derivatization of 50 consecutive injections of a methanol extraction of a filter collected in the Sierra Nevada of California. Responses of 1410 peaks in each injection were compared to the average response of each peak. This comparison is shown for (a) the injection in the middle of the series, where pink circles show all peaks compared and red squares show peaks binned by size into 10 equal bins (140 peaks each). (b) The slope (red circles) and correlation coefficient (blue squares) are shown for all comparisons in the series. Perfect correlation (slope $=1, r^{2}=1$ ) is shown as a dashed line.

variability, which is known to affect transfer efficiency. Reproducibility is instead achieved by correcting changes in derivatization and sample transfer efficiency by using isotopically labeled internal standards injected into each sample. The extent to which derivatization is reproducible and these errors can be corrected is quantified by comparing internal standards to each other; e.g., in a perfect correction scenario all compounds suffer the same changes in efficiency, so the ratio of any two compounds is unchanging and derivatization can be said to be reproducible, or at least predictable and therefore quantifiable. In a non-ideal correction scenario, some fluctuation of this ratio is expected, so correction/reproducibility error is quantified as the relative standard deviation $(\sigma)$ from the average of a ratio of two internal standards. The error from various possible correction scenarios is presented in Fig. 4 and Table 1 using response of internal standards injected on top of a wide range of organic loadings.

Figure 4 highlights the correction scenarios that apply to operational conditions typically used in deployment of SV- 
A. $n$-Alkanes compared to $n$-alkanes of similar volatility
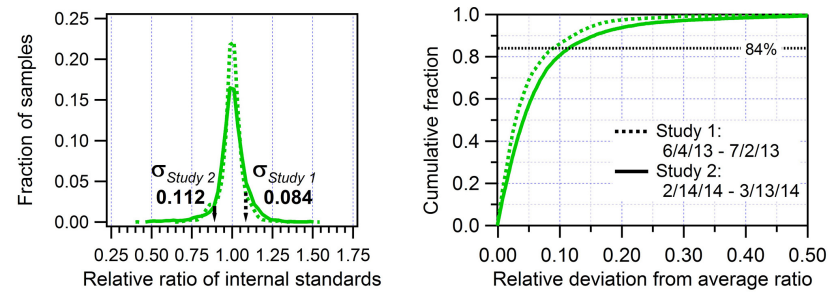

B. $n$-Acids compared to $n$-acids of various volatilies
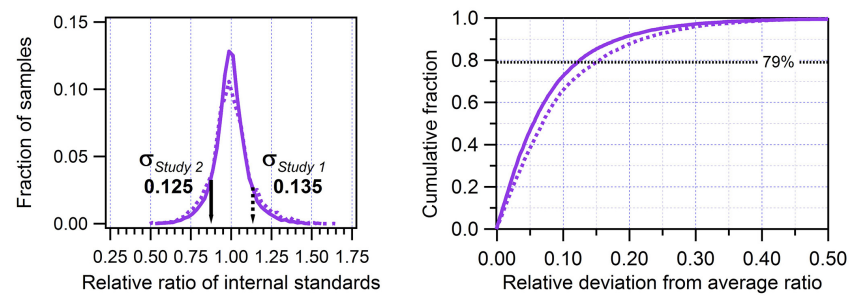

C. $n$-Acids compared to $n$-acids of similar volatility
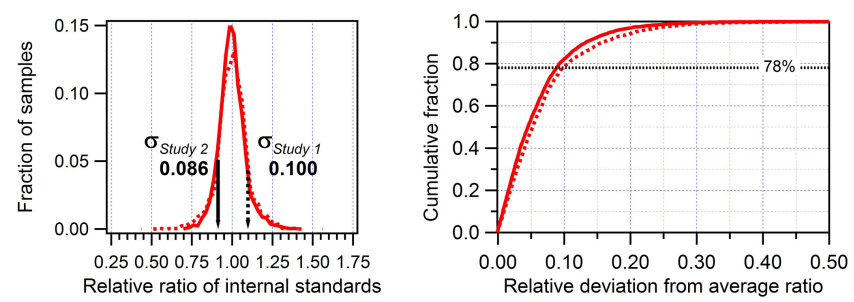

Figure 4. The ratio of two internal standards relative to their average ratio, with relative standard deviations shown. Distributions of error from two periods of field data collection (dashed: Study 1; solid: Study 2) are shown for scenarios most closely representing operating conditions of TAG: (a) correction of alkanes using alkanes with similar volatilities to quantify precision in hydrocarbon measurement, (b) correction of alkanoic acids using randomly assigned alkanoic acids to quantify precision in most oxygenate measurements, and (c) correction of alkanoic acids using the alkanoic acid closest in volatility to quantify precision in analytes for which a very similar internal standard is present. In all cases, approximately $80 \%$ of all samples fall within the standard deviation of the average (exact percentage in each scenario shown as dotted line).

TAG with derivatization. Given the wide range of alkanes present in the internal standard, perdeuterated alkanes that are close in volatility can be used to correct variability in response to hydrocarbon analytes. The ratio of one perdeuterated alkane (representing a hydrocarbon analyte) to the next closest in volatility has a relative standard deviation of $8.4 \%$ (Fig. 4a) during Study 1 and $11.2 \%$ during Study 2. More than $80 \%$ of all points fall within these standard deviations. Transfer efficiency can change dramatically between two carbon numbers for species of high molecular weight, so a large fraction of this error is due to real differences in response caused by variations in sample loading; when considering only hydrocarbons not affected strongly by transfer efficiency changes (smaller than $\mathrm{C}_{28}$ ), such as sesquiterpenes, standard deviation of error for Study 2 is reduced to $6.1 \%$.
Error in correction for run-to-run changes in derivatization efficiency depends strongly on available internal standards due to its dependence on functionality. In typical field deployment of TAG, most atmospherically relevant oxygenated compound classes that can be detected by thermal desorption, derivatized GC are represented by at least one internal (isotopically labeled) standard: mono-carboxylic acids, dicarboxylic acids, polyols, sugars, and hydroxy acids. Most of these compound classes are limited to only one internal standard due to cost and availability of isotopically labeled standards, but several perdeuterated $n$-alkanoic acids are present. The ratio of one $n$-alkanoic acid to another with no regard to volatility therefore serves as a reasonable model for error in correction of run-to-run variability of identified compounds and therefore applies broadly to most oxygenated compounds measured in typical SV-TAG operation. Figure $4 \mathrm{~b}$ is the result of assigning each of four perdeuterated $n$-acids randomly to each other 10 times. Based on this representative scenario, the measurement precision is found to have a standard deviation of $13 \%$ for any compound for which a reasonably chemically similar internal standard is used under normal operating conditions. This is higher than the error inherent in hydrocarbon correction as it includes variability in derivatization efficiency, an additional source of error. To reduce error, compounds may be targeted with specific internal standards (i.e., pentaerythritol-2- ${ }^{13} \mathrm{C}$ to accurately quantify 2-methyltetrols, a common biogenic oxidation product). Error for such a targeted compound is best modeled by correcting $n$-acids using the next-nearest $n$-acid in volatility (Fig. 4c) to represent correction using an internal standard that is both chemically and structurally similar. This scenario has an error of approximately $10 \%$ in correction for run-to-run variability. In both scenarios shown for correction of oxygenates, standard deviations encompass nearly $80 \%$ of the error (dotted lines in Fig. 4).

The scenarios for error in Fig. 4 are those that apply to most compounds under typical operation of TAG. However, error depends on the availability of chemically similar standards, so estimates of error have been provided in Table 1 for various scenarios representing possible selections of internal standards (scenarios highlighted in Fig. 4 are shown in bold).

In the absence of a wide array of internal standards, a small range of oxygenates can be used with similar functionality (scenario 4) or volatility (scenarios 3,5 ) with an error of 20 $30 \%$. Note that, based on scenario 3 , an oxygenated compound can be measured with a precision of $\sim 20 \%$ even in the absence of definitive identification, providing an estimate of error in cases where absolute concentrations are unnecessary such as comparison between parallel sampling cells. If necessary, a single oxygenate can be used to correct simply for overall changes in derivatization efficiency (scenario 6), with a corresponding increase in error (30-40\%). However, correction of oxygenates using hydrocarbon internal standards (scenarios 7,8 ) results in a significantly non-Gaussian distribution of errors and very high error (see the Supplement 
Table 1. Standard deviation in error for correction of run-to-run variability of oxygenates using a variety of possible scenarios for pairing analytes to internal standards. Full distribution of error for scenarios in bold are shown in Fig. 4. In all cases, "nearest" refers to closest in volatility.

\begin{tabular}{|c|c|c|c|}
\hline \# & Internal standard used & Standarc & eviation \\
\hline & \multicolumn{3}{|c|}{ Oxygenate to oxygenate } \\
\hline & & Study 1 & Study 2 \\
\hline 1 & Random $n$-acid ( $n$-acids only) & $13.5 \%$ & $12.5 \%$ \\
\hline 2 & Nearest $n$-acid ( $n$-acids only) & $10.0 \%$ & $8.6 \%$ \\
\hline 3 & Nearest $n$-acid ${ }^{1}$ & $32.5 \%$ & $21.1 \%$ \\
\hline 4 & Similar number of $\mathrm{OH}$ groups ${ }^{2}$ & $36.7 \%$ & $20.4 \%$ \\
\hline 5 & Nearest oxygenate & $38.0 \%$ & $24.0 \%$ \\
\hline 6 & Octadecanoic acid ${ }^{1}$ & $36.0 \%$ & $27.3 \%$ \\
\hline
\end{tabular}

Oxygenate to hydrocarbon

\begin{tabular}{llll}
\hline 7 & Octadecane & $61.5 \%^{3}$ & $36.7 \%^{3}$ \\
8 & Nearest alkane $^{1}$ & $61.1 \%^{3}$ & $32.5 \%^{3}$ \\
\hline
\end{tabular}

${ }^{1}$ Cumulative distribution of error shown in the Supplement; ${ }^{2}$ nearest oxygenate with same number or $\pm 1 \mathrm{OH}$ group; ${ }^{3}$ strongly non-Gaussian error, poorly represented by standard deviation.

for cumulative error distribution), indicating that there are some relevant changes in derivatization efficiency that must be corrected for with oxygenated internal standards. For scenarios involving correction using relatively similar internal standards, error is found to be similar across both instrument deployments despite varying environmental conditions owing to the use of a large suite of internal standards. However, error estimates diverge under scenarios modeling the use of less similar internal standards, with some reduction in error following instrument modifications between campaigns. This highlights the importance of careful internal standard selection and the benefits of employing atmospherically relevant internal standards.

\subsection{Quantitation}

Linear response of derivatized compounds within the range of expected analyte abundances is necessary for accurate quantification of oxygenated tracer compounds. A suite of over 100 authentic standards was injected at various levels two to three times per day throughout Study 1 during the SOAS field campaign. Daily schedules typically included injection of a single AutoInject loop of "concentrated" standard (12-32 ng of each compound) and one injection of one to three loops of "dilute" standard (1.2-3.2 ng of each compound per loop), with occasional injections of two loops of concentrated standard. Once corrected for variability using internal standards (per Sect. 3.2), calibration curves were found to be linear in nearly all cases. Examples of four calibration curves spanning several atmospherically relevant functional classes are shown in Fig. 5, with
A.

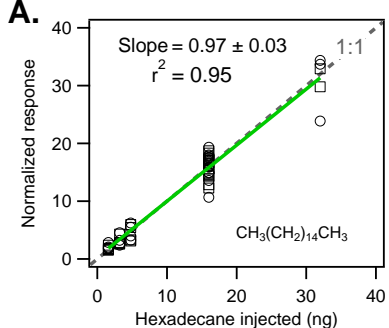

C.
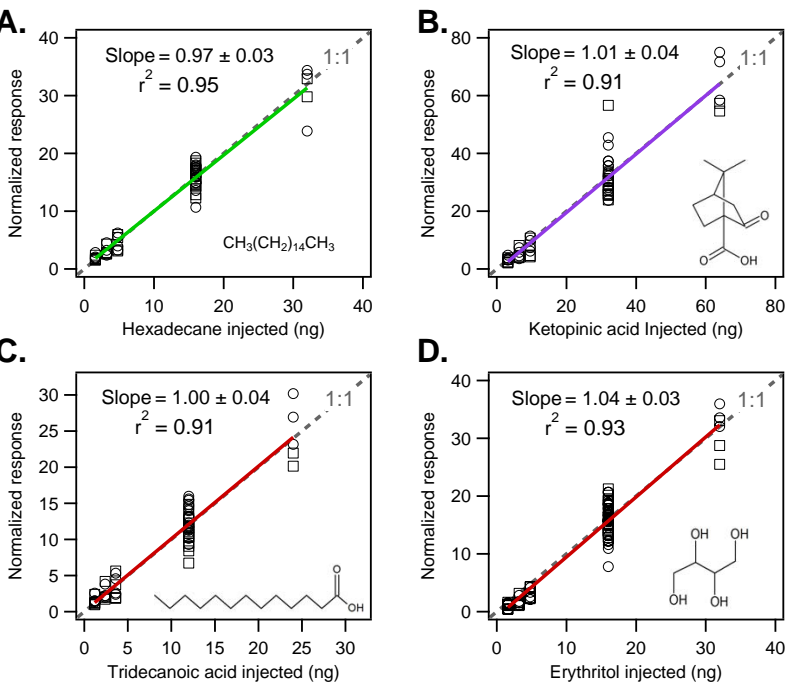

D.

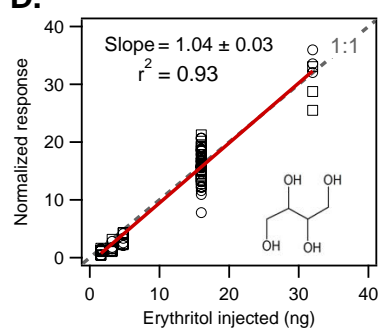

Figure 5. One month of multi-point calibrations of sample compounds during Study 1 (both cells shown as circles and squares). Response is corrected using a structurally similar deuterated internal standard injected into every run, as is standard operating procedure to correct for run-to-run variability (line color represents the scenario of correction from Fig. 4). The average response of the instrument to one loop of concentrated standard is used to normalize all data to demonstrate $1: 1$ linearity.

quantities injected that are approximately in the range expected in the atmosphere for typical sample sizes, and instrument response normalized to the response of one loop of concentrated standard. Several correction scenarios shown in Fig. 4 are represented: correction of a hydrocarbon using a hydrocarbon of similar volatility (Fig. 5a: hexadecane corrected using hexadecane- $\mathrm{d}_{34}$ ), correction of an oxygenate using an oxygenate of similar functionality (Fig. 5b: ketopinic acid, a mono-carboxylic acid, biogenic oxidation product corrected using tetradecanoic acid- $\mathrm{d}_{27}$ ), and correction of an oxygenate (alkanoic acid) using a nearly identical oxygenate (Fig. 5c: tridecanoic acid corrected using tetradecanoic acid$\mathrm{d}_{27}$; Fig. 5d: erythritol corrected using pentaerythritol-2${ }^{13} \mathrm{C}$ ).

Calibrations are in all cases linear, and spread in the data is typically limited to $10-20 \%$, within the precision error for run-to-run variability correction estimated by detailed error analysis in Sect. 3.2. Following correction by internal standards, both cells fall on the same calibration curves because any difference in sensitivity to a compound between the cells is mirrored in the sensitivity to a chemically similar internal standard. Consequently, uncertainty in mass concentrations is dominated by the correction for instrument and derivatization variability. As the ratio of signal from both cells, uncertainties in variability correction combine to yield approximately $20-25 \%$ uncertainty in particle fraction. The Supplement contains a discussion of propagation of error in mass calibration, equalization between the two cells, and calcula- 


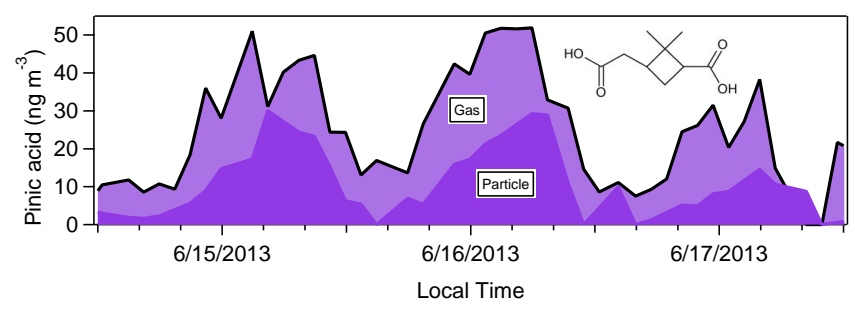

Figure 6. Sample final data of pinic acid, a known tracer for the oxidation of $\alpha$-pinene, a common biogenically emitted monoterpene. Gas-phase concentration (light purple) is measured as the difference between total concentration (black line) and particle-phase concentration (dark purple).

tion of particle fraction, as well as the equations necessary to calculate uncertainty on a point-by-point basis.

Sensitivity to compounds is dependent on functionality, such that limits of detection and quantitation are compound specific. Calibrations shown in Fig. 5 extend down to approximately $1-2$ ng injected mass, though in most cases analyte signal at this level is still 10-100 times chromatographic background signals. As an example, erythritol as shown in Fig. 5d during Study 1 is 20 times larger than background at $1.6 \mathrm{ng}$, and during Period 2 it is 10 times larger than background at $0.6 \mathrm{ng}$. Consequently, though limits of detection must be calculated individually for each analyte of interest, a reasonable average estimate is on the order of tenths of a nanogram, though in some cases it is lower than $0.1 \mathrm{ng}$. When operating with hourly time resolution, sample is collected for approximately $20 \mathrm{~min}$ at $10 \mathrm{Lpm}$, yielding conservative limits of detection of $1-2 \mathrm{ng} \mathrm{m}^{-3}(\sim 0.1 \mathrm{ppt})$, which is below measured concentrations for most analytes of interest. However, detection limits can be arbitrarily scaled through increasing or sacrificing sampling time and therefore time resolution. Though sample and injected standards sit on cell 2 throughout desorption of cell 1 , there is no indication of a loss of volatile compounds. Carryover of sample from one cell into the other cell or subsequent sample occurs independent of volatility at less than $3 \%$ (Kreisberg et al., 2014).

\subsection{Sample field data}

A sample of the data available using dual-cell SV-TAG with derivatization is shown in Fig. 6, a short sample timeline from the SOAS field campaign. Three days of hourly concentrations of gas- and particle-phase pinic acid, a product of the atmospheric oxidation of $\alpha$-pinene, demonstrates clear diurnal variation, as well as many short spikes in concentration. These features are indicative of atmospheric and biological processes that are occurring with higher time resolution than is available using traditional measurement techniques.

\section{Conclusions}

We present here an instrument for hourly measurement of both gas- and particle-phase oxygenated organic compounds in the ambient atmosphere. Though quantification of organic tracers has provided significant insight into atmospheric oxidation chemistry and aerosol formation pathways, traditional measurement techniques require sample times of several hours to several days, as well as offline sample processing. By modifying SV-TAG, a field-deployable instrument, to include online derivatization, known and novel organic tracers can be quantified hourly in situ. Inclusion of a dualcell, parallel sampling system allows simultaneous measurement of both gas- and particle-phase components through a denuder-difference method. Automation of the dual-cell SVTAG with derivatization provides improved time resolution over traditional measurement techniques with decreased operator interaction and offline sample preparation, minimizing exposure to derivatizing agent and solvents.

Derivatization is found to be reproducible, complete, and linear in all laboratory and field tests performed. Fielddeployable, in situ derivatization of polar compounds is found to be robustly quantifiable within approximately 10$20 \%$ by using internal standards to correct for variability in detector sensitivity and derivatization efficiency (range represents similarity of internal standard to analyte). Non-polar compounds can also be measured by this instrument with an error of $<10 \%$. This quantification of error is based on realworld data with significantly changing background matrixes (polluted days, clean days, denuded samples, etc.) and is robust across two different field campaigns. Absolute error in concentrations for a given compound depends strongly on available standards. For compounds with authentic or nearly identical chemical calibration standards, error is expected to be limited to correction for derivatization and transfer efficiency as discussed in this work (i.e., $15 \%$ ), while error will increase as chemical similarity decreases between the analyte of interest and the chemical surrogate used for quantification. Quantification by chemical surrogates is estimated to yield errors between 33 and 50\% (Jaoui et al., 2005) and is therefore expected to be the main source of error for this instrument, as is the case for traditional offline methods.

Atmospheric phenomena often occur on the scale of hours (i.e., break-up of inversion layers, rain events), so the time resolution provided by dual-cell SV-TAG with derivatization will enable a far more detailed analysis of atmospheric chemical pathways with similar accuracy to lower-time-resolution techniques. Furthermore, direct, hourly measurement of gasparticle partitioning will provide observational constraints to assess the relative importance of a wide variety of partitioning pathways that have been studied in great detail in laboratory experiments. Future exploration of alternative derivatization agents is also expected to expand the utility of this instrument. 


\section{The Supplement related to this article is available online at doi:10.5194/amt-7-4417-2014-supplement.}

Acknowledgements. Instrument development work was supported by the US Department of Energy SBIR/STTR under grant DESC0004698. G. Isaacman is supported by the National Science Foundation (NSF) Graduate Research Fellowship (NSF grant: DGE 1106400). Data collection as part of the SOAS field campaign was funded by NSF Atmospheric Chemistry Program grant no. 1250569. Internal standard reproducibility data collection in Brazil was thanks to the NSF Atmospheric Chemistry Program grant no. 1332998. Filter collection for the BEARPEX campaign was funded by NSF Atmospheric Chemistry Program grant no. 0922562.

Edited by: P. Herckes

\section{References}

Blau, K. and Halket, J. M. (Eds.): Handbook of Derivatives for Chromatography, 2nd Edn., John Wiley \& Sons, England, 1993.

Cass, G. R.: Organic molecular tracers for particulate air pollution sources, Trend Anal. Chem., 17, 356-366, doi:10.1016/S01659936(98)00040-5, 1998.

Chan, M. N., Surratt, J. D., Claeys, M., Edgerton, E. S., Tanner, R. L., Shaw, S. L., Zheng, M., Knipping, E. M., Eddingsaas, N. C., Wennberg, P. O., and Seinfeld, J. H.: Characterization and quantification of isoprene-derived epoxydiols in ambient aerosol in the southeastern United States, Environ. Sci. Technol., 44, 45904596, doi:10.1021/es100596b, 2010.

Claeys, M., Wang, W., Ion, A. C., Kourtchev, I., Gelencsér, A. and Maenhaut, W.: Formation of secondary organic aerosols from isoprene and its gas-phase oxidation products through reaction with hydrogen peroxide, Atmos. Environ., 38, 4093-4098, doi:10.1016/j.atmosenv.2004.06.001, 2004.

Claeys, M., Szmigielski, R., Kourtchev, I., van der Veken, P., Vermeylen, R., Maenhaut, W., Jaoui, M., Kleindienst, T. E., Lewandowski, M., Offenberg, J. H., and Edney, E. O.: Hydroxydicarboxylic acids: markers for secondary organic aerosol from the photooxidation of alpha-pinene, Environ. Sci. Technol., 41, 1628-1634, 2007.

Claeys, M., Iinuma, Y., Szmigielski, R., Surratt, J. D., Blockhuys, F., van Alsenoy, C., Boge, O., Sierau, B., Gomez-Gonzalez, Y., Vermeylen, R., van Der Veken, P., Shahgholi, M., Chan, A. W. H., Herrmann, H., Seinfeld, J. H., and Maenhaut, W.: Terpenylic Acid and Related Compounds from the Oxidation of a-Pinene: Implications for New Particle Formation and Growth above Forests, Environ. Sci. Technol., 43, 6976-6982, 2009.

Docherty, K. S. and Ziemann, P. J.: On-line, inlet-based trimethylsilyl derivatization for gas chromatography of mono- and dicarboxylic acids, J. Chromatogr. A, 921, 265-275, 2001.

Edney, E. O., Kleindienst, T. E., Conver, T., McIver, C., Corse, E., and Weathers, W.: Polar organic oxygenates in PM2.5 at a southeastern site in the United States, Atmos. Environ., 37, 39473965, doi:10.1016/S1352-2310(03)00461-8, 2003.

Fluka Chemie AG: Silylating Agents, Buchs, Switzerland, 1995.
Fraser, M. P. and Lakshmanan, K.: Using Levoglucosan as a Molecular Marker for the Long-Range Transport of Biomass Combustion Aerosols, Environ. Sci. Technol., 34, 4560-4564, doi:10.1021/es9912291, 2000.

Fraser, M. P., Cass, G. R., and Simoneit, B. R. T.: Gas-Phase and Particle-Phase Organic Compounds Emitted from Motor Vehicle Traffic in a Los Angeles Roadway Tunnel, Environ. Sci. Technol., 32, 2051-2060, 1998.

Fraser, M. P., Cass, G. R., and Simoneit, B. R. T.: Particulate organic compounds emitted from motor vehicle exhaust and in the urban atmosphere, Atmos. Environ., 33, 2715-2724, doi:10.1016/S1352-2310(98)00311-2, 1999.

Gao, S., Surratt, J. D., Knipping, E. M., Edgerton, E. S., Shahgholi, M., and Seinfeld, J. H.: Characterization of polar organic components in fine aerosols in the southeastern United States: Identity, origin, and evolution, J. Geophys. Res., 111, D14314, doi:10.1029/2005JD006601, 2006.

Goldstein, A. H. and Galbally, I.: Known and unexplored organic constituents in the earth's atmosphere, Environ. Sci. Technol., 41, 1514-1521, 2007.

Hallquist, M., Wenger, J. C., Baltensperger, U., Rudich, Y., Simpson, D., Claeys, M., Dommen, J., Donahue, N. M., George, C., Goldstein, A. H., Hamilton, J. F., Herrmann, H., Hoffmann, T., Iinuma, Y., Jang, M., Jenkin, M. E., Jimenez, J. L., Kiendler-Scharr, A., Maenhaut, W., McFiggans, G., Mentel, Th. F., Monod, A., Prévôt, A. S. H., Seinfeld, J. H., Surratt, J. D., Szmigielski, R., and Wildt, J.: The formation, properties and impact of secondary organic aerosol: current and emerging issues, Atmos. Chem. Phys., 9, 5155-5236, doi:10.5194/acp-9-51552009, 2009.

Hamilton, J. F.: Using comprehensive two-dimensional gas chromatography to study the atmosphere, J. Chrom. Sci., 48, 274282, 2010.

Hildemann, L. M., Mazurek, M. A., Cass, G. R., and Simoneit, B. R. T.: Quantitative Characterization of Urban Sources of Organic Aerosol by High-Resolution Gas Chromatography, Environ. Sci. Technol., 25, 1311-1325, 1991.

Isaacman, G., Kreisberg, N. M., Worton, D. R., Hering, S. V., and Goldstein, A. H.: A versatile and reproducible automatic injection system for liquid standard introduction: application to in-situ calibration, Atmos. Meas. Tech., 4, 1937-1942, doi:10.5194/amt-4-1937-2011, 2011.

Jaoui, M., Kleindienst, T. E., Lewandowski, M., Offenberg, J. H., and Edney, E. O.: Identification and quantification of aerosol polar oxygenated compounds bearing carboxylic or hydroxyl groups. 2. Organic tracer compounds from monoterpenes, Environ. Sci. Technol., 39, 5661-5673, 2005.

Jaoui, M., Lewandowski, M., Kleindienst, T. E., Offenberg, J. H., and Edney, E. O.: $\beta$-caryophyllinic acid: An atmospheric tracer for $\beta$-caryophyllene secondary organic aerosol, Geophys. Res. Lett., 34, L05816, doi:10.1029/2006GL028827, 2007.

Jimenez, J. L., Canagaratna, M. R., Donahue, N. M., Prevot, A. S. H., Zhang, Q., Kroll, J. H., DeCarlo, P. F., Allan, J. D., Coe, H., Ng, N. L., Aiken, A. C., Docherty, K. S., Ulbrich, I. M., Grieshop, A. P., Robinson, A. L., Duplissy, J., Smith, J. D., Wilson, K. R., Lanz, V. A., Hueglin, C., Sun, Y. L., Tian, J., Laaksonen, A., Raatikainen, T., Rautiainen, J., Vaattovaara, P., Ehn, M., Kulmala, M., Tomlinson, J. M., Collins, D. R., Cubison, M. J., Dunlea, E. J., Huffman, J. A., Onasch, T. B., Alfarra, M. R., 
Williams, P. I., Bower, K., Kondo, Y., Schneider, J., Drewnick, F., Borrmann, S., Weimer, S., Demerjian, K., Salcedo, D., Cottrell, L., Griffin, R. J., Takami, A., Miyoshi, T., Hatakeyama, S., Shimono, A., Sun, J. Y., Zhang, Y. M., Dzepina, K., Kimmel, J. R., Sueper, D., Jayne, J. T., Herndon, S. C., Trimborn, A. M., Williams, L. R., Wood, E. C., Middlebrook, A. M., Kolb, C. E., Baltensperger, U., and Worsnop, D. R.: Evolution of Organic Aerosols in the Atmosphere, Science, 326, 1525-1529, doi:10.1126/science.1180353, 2009.

Kamens, R. M. and Coe, D. L.: Research Communications A Large Gas-Phase Stripping Device to Investigate Rates of PAH Evaporation from Airborne Diesel Soot Particles, Environ. Sci. Technol., 31, 1830-1833, 1997.

Kleindienst, T. E., Jaoui, M., Lewandowski, M., Offenberg, J. H., Lewis, C. W., Bhave, P. V., and Edney, E. O.: Estimates of the contributions of biogenic and anthropogenic hydrocarbons to secondary organic aerosol at a southeastern US location, Atmos. Environ., 41, 8288-8300, doi:10.1016/j.atmosenv.2007.06.045, 2007.

Kleindienst, T. E., Lewandowski, M., Offenberg, J. H., Jaoui, M., and Edney, E. O.: The formation of secondary organic aerosol from the isoprene $+\mathrm{OH}$ reaction in the absence of $\mathrm{NO}_{\mathrm{x}}$, Atmos. Chem. Phys., 9, 6541-6558, doi:10.5194/acp-9-6541-2009, 2009.

Kleindienst, T. E., Lee, S., Wang, Y., Russell, A. G., Doraiswamy, P., Hogrefe, C., Hao, W., Civerolo, K., Ku, J.-Y., Sistla, G., Fu, F., Tian, B., Lin, G., Chen, Y., Zhang, J., Hung, N., Ketzel, M., Jensen, S., Oanh, N., Kang, C.-M., Koutrakis, P., Suh, H., Marsik, T., Johnson, R., Soelberg, N., Enneking, J., Spicer, C., Joseph, D., Ollison, W., Chow, J., Watson, J., Green, M., Frank, N., Fulper, C., Kishan, S., Baldauf, R. W., Sabisch, M., Warila, J., Scarbro, C., Fujita, E., Crews, W., Snow, R., Gabele, P., Lewandowski, M., Offenberg, J. H., Edney, E. O., Jaoui, M., Zheng, M., Ding, X., and Edgerton, E. S.: Contribution of Primary and Secondary Sources to Organic Aerosol and PM2.5 at SEARCH Network Sites, J. Air Waste Manage., 60, 1388-1399, doi:10.3155/1047-3289.60.11.1388, 2010.

Kourtchev, I., Ruuskanen, T., Maenhaut, W., Kulmala, M., and Claeys, M.: Observation of 2-methyltetrols and related photo-oxidation products of isoprene in boreal forest aerosols from Hyytiälä, Finland, Atmos. Chem. Phys., 5, 2761-2770, doi:10.5194/acp-5-2761-2005, 2005.

Kreisberg, N. M., Hering, S. V., Williams, B. J., Worton, D. R., and Goldstein, A. H.: Quantification of Hourly Speciated Organic Compounds in Atmospheric Aerosols, Measured by an In-Situ Thermal Desorption Aerosol Gas Chromatograph (TAG), Aerosol Sci. Technol., 43, 38-52, doi:10.1080/02786820802459583, 2009.

Kreisberg, N. M., Worton, D. R., Zhao, Y., Isaacman, G., Goldstein, A. H., and Hering, S. V.: Development of an automated hightemperature valveless injection system for online gas chromatography, Atmos. Meas. Tech., 7, 4431-4444, doi:10.5194/amt-74431-2014, 2014.

Kroll, J. H. and Seinfeld, J. H.: Chemistry of seckreisbergondary organic aerosol: Formation and evolution of low-volatility organics in the atmosphere, Atmos. Environ., 42, 3593-3624, doi:10.1016/j.atmosenv.2008.01.003, 2008.

Kubátová, A., Vermeylen, R., and Claeys, M.: Organic compounds in urban aerosols from Gent, Belgium: Characterization, sources, and seasonal differences, J. Geophys. Res., 107, ICC 5-1 to ICC 5-12, doi:10.1029/2001JD000556, 2002.

Lewandowski, M., Jaoui, M., Kleindienst, T. E., Offenberg, J. H. and Edney, E. O.: Composition of PM2.5 during the summer of 2003 in Research Triangle Park, North Carolina, Atmos. Environ., 41, 4073-4083, doi:10.1016/j.atmosenv.2007.01.012, 2007.

Lough, G., Schauer, J. J., and Lawson, D.: Day-of-week trends in carbonaceous aerosol composition in the urban atmosphere, Atmos. Environ., 40, 4137-4149, doi:10.1016/j.atmosenv.2006.03.009, 2006.

Mazurek, M. A.: Molecular Identification of Organic Compounds in Atmospheric Complex Mixtures and Relationship to Atmospheric Chemistry and Sources, Environ. Health Persp., 110, 995-1003, 2002.

Offenberg, J. H., Lewandowski, M., Jaoui, M., and Kleindienst, T. E.: Contributions of Biogenic and Anthropogenic Hydrocarbons to Secondary Organic Aerosol during 2006 in Research Triangle Park, NC, Aerosol Air Qual. Res., 11, 99-108, doi:10.4209/aaqr.2010.11.0102, 2011.

Orasche, J., Schnelle-Kreis, J., Abbaszade, G., and Zimmermann, R.: Technical Note: In-situ derivatization thermal desorption GC-TOFMS for direct analysis of particle-bound non-polar and polar organic species, Atmos. Chem. Phys., 11, 8977-8993, doi:10.5194/acp-11-8977-2011, 2011.

Oss, M., Kruve, A., Herodes, K. and Leito, I.: Electrospray Ionization Efficiency Scale of Organic Compounds, Anal. Chem., 82, 2865-2872, 2010.

Ramdahl, T.: Retene - a molecular marker of wood combustion in ambient air, Nature, 306, 580-582, 1983.

Ruehl, C. R., Nah, T., Isaacman, G., Worton, D. R., Chan, A. W. H., Kolesar, K. R., Cappa, C. D., Goldstein, A. H., and Wilson, K. R.: The Influence of Molecular Structure and Aerosol Phase on the Heterogeneous Oxidation of Normal and Branched Alkanes by OH, J. Phys. Chem. A, 117, 3990-4000, 2013.

Schauer, J. J., Rogge, W. F., Hildemann, L. M., Mazurek, M. A., and Cass, G. R.: Source apportionment of airborne particulate matter using organic compounds as tracers, Atmos. Environ., 30, 3837-3855, 1996.

Schauer, J. J., Kleeman, M. J., Cass, G. R., and Simoneit, B. R. T.: Measurement of Emissions from Air Pollution Sources. 1. C 1 through C 29 Organic Compounds from Meat Charbroiling, Environ. Sci. Technol., 33, 1566-1577, doi:10.1021/es980076j, 1999a.

Schauer, J. J., Kleeman, M. J., Cass, G. R., and Simoneit, B. R. T.: Measurement of Emissions from Air Pollution Sources. 2. C 1 through C 30 Organic Compounds from Medium Duty Diesel Trucks, Environ. Sci. Technol., 33, 1578-1587, doi:10.1021/es980081n, 1999b.

Schauer, J. J., Kleeman, M. J., Cass, G. R., and Simoneit, B. R. T.: Measurement of Emissions from Air Organic Compounds from Gasoline-Powered Motor Vehicles, Environ. Sci. Technol., 36, 1169-1180, 2002

Sheesley, R. J., Deminter, J. T., Meiritz, M., Snyder, D. C. and Schauer, J. J.: Temporal trends in motor vehicle and secondary organic tracers using in situ methylation thermal desorption GCMS, Environ. Sci. Technol., 44, 9398-9404, doi:10.1021/es102301t, 2010. 
Simoneit, B. R. T.: A review of current applications of mass spectrometry for biomarker/molecular tracer elucidation, Mass Spectrom. Rev., 24, 719-765, doi:10.1002/mas.20036, 2005.

Storey, J. M. E., Luo, W., Isabelle, L. M., and Pankow, J. F.: Gas/Solid Partitioning of Semivolatile Organic Compounds to Model Atmospheric Solid Surfaces as a Function of Relative Humidity. 1. Clean Quartz, Environ. Sci. Technol., 29, 2420-2428, 1995.

Surratt, J. D., Go, Y., Chan, A. W. H., Vermeylen, R., Shahgholi, M., Kleindienst, T. E., Edney, E. O., Offenberg, J. H., Lewandowski, M., Jaoui, M., Maenhaut, W., Claeys, M., Flagan, R. C., and Seinfeld, J. H.: Organosulfate Formation in Biogenic Secondary Organic Aerosol, J. Phys. Chem. A, 112, 8345-8378, 2008.

Szmigielski, R., Surratt, J. D., Vermeylen, R., Szmigielska, K., Kroll, J. H., Ng, N. L., Murphy, S. M., Sorooshian, A., Seinfeld, J. H., and Claeys, M.: Characterization of 2-methylglyceric acid oligomers in secondary organic aerosol formed from the photooxidation of isoprene using trimethylsilylation and gas chromatography / ion trap mass spectrometry, J. Mass Spectrom., 42, 101-116, doi:10.1002/jms.1146, 2007.

Williams, B. J., Goldstein, A. H., Kreisberg, N. M., and Hering, S. V.: An In-Situ Instrument for Speciated Organic Composition of Atmospheric Aerosols: Thermal Desorption Aerosol GC/MS-FID (TAG), Aerosol Sci. Technol., 40, 627638, doi:10.1080/02786820600754631, 2006.

Williams, B. J., Goldstein, A. H., Kreisberg, N. M., and Hering, S. V.: In situ measurements of gas/particle-phase transitions for atmospheric semivolatile organic compounds, P. Natl. Acad. Sci. USA, 107, 6676-6681, doi:10.1073/pnas.0911858107, 2010a.

Williams, B. J., Goldstein, A. H., Kreisberg, N. M., Hering, S. V., Worsnop, D. R., Ulbrich, I. M., Docherty, K. S., and Jimenez, J. L.: Major components of atmospheric organic aerosol in southern California as determined by hourly measurements of source marker compounds, Atmos. Chem. Phys., 10, 11577-11603, doi:10.5194/acp-10-11577-2010, 2010 b.

Worton, D. R., Goldstein, A. H., Farmer, D. K., Docherty, K. S., Jimenez, J. L., Gilman, J. B., Kuster, W. C., de Gouw, J., Williams, B. J., Kreisberg, N. M., Hering, S. V., Bench, G., McKay, M., Kristensen, K., Glasius, M., Surratt, J. D., and Seinfeld, J. H.: Origins and composition of fine atmospheric carbonaceous aerosol in the Sierra Nevada Mountains, California, Atmos. Chem. Phys., 11, 10219-10241, doi:10.5194/acp-1110219-2011, 2011.
Zhang, H., Ruehl, C. R., Chan, A. W. H., Nah, T., Worton, D. R., Isaacman, G., Goldstein, A. H., and Wilson, K. R.: OH-initiated heterogeneous oxidation of cholestane: a model system for understanding the photochemical aging of cyclic alkane aerosols, J. Phys. Chem. A, 117, 12449-12458, doi:10.1021/jp407994m, 2013.

Zhang, Q., Jimenez, J. L., Canagaratna, M. R., Allan, J. D., Coe, H., Ulbrich, I. M., Alfarra, M. R., Takami, A., Middlebrook, A. M., Sun, Y. L., Dzepina, K., Dunlea, E J., Docherty, K. S., DeCarlo, P. F., Salcedo, D., Onasch, T. B., Jayne, J. T., Miyoshi, T., Shimono, A., Hatakeyama, S., Takegawa, N., Kondo, Y., Schneider, J., Drewnick, F., Borrmann, S., Weimer, S., Demerjian, K., Williams, P., Bower, K., Bahreini, R., Cottrell, L., Griffin, R. J., Rautiainen, J., Sun, J. Y., Zhang, Y. M., and Worsnop, D. R.: Ubiquity and dominance of oxygenated species in organic aerosols in anthropogenically-influenced Northern Hemisphere midlatitudes, Geophys. Res. Lett., 34, L13801, doi:10.1029/2007GL029979, 2007.

Zhang, Y., Sheesley, R. J., Schauer, J. J., Lewandowski, M., Jaoui, M., Offenberg, J. H., Kleindienst, T. E., and Edney, E. O.: Source apportionment of primary and secondary organic aerosols using positive matrix factorization (PMF) of molecular markers, Atmos. Environ., 43, 5567-5574, doi:10.1016/j.atmosenv.2009.02.047, 2009.

Zhao, Y., Kreisberg, N. M., Worton, D. R., Isaacman, G., Weber, R. J., Liu, S., Day, D. A., Russell, L. M., Markovic, M. Z., Vandenboer, T. C., Murphy, J. G., Hering, S. V., and Goldstein, A. H.: Insights into secondary organic aerosol formation mechanisms from measured gas/particle partitioning of specific organic tracer compounds, Environ. Sci. Technol., 47, 3781-3787, doi:10.1021/es304587x, 2013a.

Zhao, Y., Kreisberg, N. M., Worton, D. R., Teng, A. P., Hering, S. V. and Goldstein, A. H.: Development of an In Situ Thermal Desorption Gas Chromatography Instrument for Quantifying Atmospheric Semi-Volatile Organic Compounds, Aerosol Sci. Technol., 47, 258-266, doi:10.1080/02786826.2012.747673, 2013b. 